\title{
Improved economics of HBsAg screening with commercial radioimmunoassay reagents
}

\author{
R HOPKINS, SYLVIA ROSS, T JORDAN, AND AD WATT \\ From the Microbiology Division, South-East Scotland Regional Transfusion Centre, Royal Infirmary, \\ Edinburgh, UK
}

SUMMARY Commercial ${ }^{125}$ I anti-HBs was processed to yield a sixfold improvement in economy without significant loss of sensitivity or specificity. Additional polystyrene beads were coupled with commercially supplied anti-HBs. The modified assay (Mod-RIA) was compared with commercial RIA, EIA, and RPHA using established HBsAg panels. Mod-RIA was also compared with HEPATEST (RPHA) for screening 71200 fresh blood donations during an 11.5-month period.

Solid-phase sandwich radioimmunoassay (RIA), particularly that marketed by Abbott Laboratories under the name AUSRIA-II, remains the most reliable screening test for hepatitis B surface antigen (HBsAg) despite the current strong challenge by enzyme immunoassay (EIA). $1,2,3,4$ Unfortunately, the price per test of commercial RIA has proved prohibitive for many transfusion centres restricted to the cheaper and less sensitive reverse passive haemagglutination test (RPHA). ${ }^{5}$

With some types of assay it is possible to reduce costs by using home-made rather than commercial reagents. ${ }^{6}$ Many transfusion centres have neither the expertise nor the facilities to produce reagents that require specific protein purification with subsequent radiolabelling. In these circumstances the most that can be achieved in economic terms is a reduction in costs accruing from bulk purchase of commercial reagent. This communication presents evidence that the 125I-labelled anti-HBs in the AUSRIA-II RIA kit may be quickly, simply, and routinely processed and diluted to provide sufficient reagent for an average of six times as many assays without significant loss of sensitivity or specificity and without necessitating an increase in incubation time.

\section{Material and methods}

REAGENTS AND EQUIPMENT

$16.5 \mathrm{~mm}$ diameter polystyrene beads (white and tinted) are obtainable from the Precision Plastic Ball Company, 3000 North Cicero Avenue, Chicago, Illinois 60641, USA. In the UK these

Received for publication 14 August 1979 same beads may be purchased from Northumbria Biologicals Ltd, South Nelson Industrial Estate, Cramlington, Northumberland.

2 Lyophilised Anti-HBs (horse), supplied by Wellcome Reagents Ltd (code IP23).

3 125I anti-HBs (human) supplied as part of the AUSRIA-II RIA kit (Abbott Laboratories). Unfortunately, this reagent is not available as a separate component.

4 Polyethylene Glycol 6000 (BDH).

$50.02 \mathrm{M}$ TRIS/HCl $+0.1 \mathrm{M} \mathrm{NaCl} \mathrm{pH} 7.6+1 \mathrm{mg} /$ $\mathrm{ml} \mathrm{NaN}$.

6 Sterile distilled water.

7 Normal human serum (negative for HBsAg and anti-HBs by RIA).

8 Bench centrifuge with sealed rotor.

9 Matburn mixer.

10 Coulter roller.

11 Balance.

12 Reagent dispenser capable of accurately delivering $200 \mu \mathrm{l}$ volumes.

13 Gamma counter. The most suitable for a laboratory required to test large numbers of samples daily is the NE 1600 (Nuclear Enterprises), which will count 16 samples simultaneously.

14 Suitable vehicle for conducting assay. AUSRIA-II trays are re-usable if soaked in detergent (RBS) overnight, rinsed, and dried.

15 System for bead washing (eg, Filamatic dispenser and Pentawash gun, available through Abbott Laboratories).

16 Means of disposal of radioactive waste.

BEAD COATING

Experience has shown that beads supplied by the 
Precision Plastic Ball Company are suitable for coating without prior cleaning. It should be borne in mind, however, that beads from other sources may first require removal of grease or resins resulting from the production process, and should be soaked in ethanol overnight, then washed thoroughly in sterile distilled water, and dried.

Each $1 \mathrm{ml}$ vial of horse anti-HBs was reconstituted in sterile distilled water as required and stored as 'stock' solution at $4^{\circ} \mathrm{C}$. Immediately before coating, the appropriate volume of stock anti-HBs was diluted to optimum coating concentration (usually 1:1000, determined with each new batch number of horse anti-HBs) in sterile distilled water in a glass MRC bottle (up to $500 \mathrm{ml}$ ), and beads were added in the ratio 1000 beads to $200 \mathrm{ml}$ diluted anti-HBs. The beads in anti-HBs were mixed continuously at $4^{\circ} \mathrm{C}$ on a Coulter roller for 48 hours, dried rapidly in a stream of warm air (approximately $45^{\circ} \mathrm{C}$, from hair dryer), and placed in the appropriate assay well. Unused (dried) beads were returned to the coating solution for use the next day. As fresh beads were coated once per week it is possible that a few will have been dried and returned to the coating solution as much as six times. This feature did not appear to influence the assay adversely.

PROCESSING OF ${ }^{125}$ I ANTI-HBS

$20 \mathrm{ml}^{125} \mathrm{I}$ anti-HBs (from 100-test AUSRIA-II kit) was mixed with $12 \cdot 5 \%$ PEG $6000(\mathrm{w} / \mathrm{v})$ in a screw-cap glass McCartney bottle at room temperature until the PEG flakes had completely dissolved (about 20 minutes). The McCartney was left at $4^{\circ} \mathrm{C}$ overnight, during which a precipitate (containing most of the ${ }^{125}$ I anti-HBs but leaving any free ${ }^{125} I$ and most of the PEG in solution) formed. The next day, the McCartney was centrifuged at near-maximum (bench centrifuge) speed for 15 minutes and the supernatant was discarded. The precipitate was dissolved in $20 \mathrm{ml} 0.02 \mathrm{M}$ TRIS/ $\mathrm{HCl}+0.1 \mathrm{M} \mathrm{NaCl}$ buffer pH 7.6 containing $50 \%$ normal human serum by mixing at room temperature for 30-45 minutes using a lead-shielded Matburn mixer. The counts per minute per $200 \mu \mathrm{l}$ of the dissolved precipitate were determined, and the volume was adjusted, using the above diluent, to approximately $20000 \mathrm{cpm} / 200 \mu \mathrm{l}$. The processed ${ }^{125}$ I anti-HBs was then stored at $4^{\circ} \mathrm{C}$ until required or until the expiry date was reached.

MOD-RIA ASSAY (for daily screening of serum samples from freshly donated blood)

1 Anti-HBs-coated beads were dispensed into suitable carriers.

$2200 \mu$ l of test serum were dispensed to cover each appropriate bead using a clean, disposable tip. Positive and negative controls were included.

3 Trays were sealed, agitated gently to ensure that beads sank, and then incubated at $45^{\circ}-50^{\circ} \mathrm{C}$ for 2 hours.

4 Beads were washed and aspirated in at least $5 \times 5 \mathrm{ml}$ tap water.

$5200 \mu$ l of processed ${ }^{125}$ I anti-HBs $(\sim 20000 \mathrm{cpm})$ was dispensed to each bead and incubated as before, but for only 60 minutes.

6 Beads were washed as before, but with $10 \times 5 \mathrm{ml}$ cycles, and transferred to suitable vessels for counting.

COUNTING, CALCULATIONS, AND

INTERPRETATION OF DATA

The NE 1600 gamma counter is capable of counting 16 samples simultaneously for ${ }^{125 I}$ activity. Before sample counting began, a 300-second background count was determined for each well. Test samples and controls were then counted for 300 seconds, the appropriate background was subtracted, and the cutoff equal to $2 \cdot 1$ times the negative control mean was determined. Samples with a $\mathrm{T} / \mathrm{N}$ ratio equal to or greater than $2 \cdot 1$ were re-washed and, if still high, confirmed by retesting and specific neutralisation (when $\mathrm{T}=$ test counts and $\mathrm{N}=$ mean count of negative controls).

COMMERCIAL (THIRD PHASE) HBSAg ASSAYS COMPARED WITH MOD-RIA

1 Reverse passive haemagglutination

(a) Hepatest (Wellcome Reagents)

(b) Auscel (Abbott Lahoratories) ${ }^{8}$

2 Raaioimmunoassay

AUSRIA-II (Abbott Laboratories) ${ }^{8}$

3 Enzymeimmunoassay

Hepanostika (Organon-Technika)

All the above were performed in accordance with the manufacturers' recommendations.

EVALUATION OF MOD-RIA USING PANELS The performance of Mod-RIA was evaluated using one Abbott Laboratories Hepatitis Sensitivity panel; one Food and Drug Administration (FDA) panel; two American Association of Blood Banks and College of American Pathologists (AABB-CAP) HBsAg Proficiency panels, and one Edinburgh University, Hepatitis Reference Laboratory panel. All panels were presented in coded form for testing.

EVALUATION OF MOD-RIA FOR ROUTINE

BLOOD DONOR SCREENING

From the middle of January to the end of December 1978, Mod-RIA was in daily use for HBsAg testing. 
The 71200 blood donations involved were also screened by Hepatest.

\section{Results}

MOD-RIA VERSUS RPHA

As anticipated, the Mod-RIA was capable of detecting much lower concentrations of HBsAg than Hepatest. This was apparent from the findings on the FDA panel (Table 1), the two AABB-CAP panels (Table 2), and the Edinburgh University's Hepatitis

Table 1 Comparison of Mod-RIA with HEPATEST using FDA panel No. $3 A$

\begin{tabular}{llllllr}
\hline \multicolumn{7}{c}{ Sample designation } \\
& SP & $P$ & $W P$ & $B L$ & $D$ & Total \\
\hline Mod-RIA & $1 / 1$ & $5 / 5$ & $9 / 9$ & $3 / 4$ & $2 / 4$ & $20 / 23$ \\
HEPATEST & $1 / 1$ & $4 / 5$ & $4 / 9$ & $0 / 4$ & $0 / 4$ & $9 / 23$
\end{tabular}

$\mathbf{S P}=$ strongly positive; $\mathbf{P}=$ positive $; \mathbf{W P}=$ weakly positive

$\mathbf{B L}=$ borderline positive $\mathbf{D}=$ diluted beyond borderline.

Table 2 Comparison of Mod-RIA with AUSRIA-II and HEPATEST using two AABB-CAP HBSAg proficiency panels

\begin{tabular}{llll}
\hline Panel & Mod-RIA & AUSRIA-II & HEPATEST \\
\hline A (w-01 to w-10) & $8 / 8$ & $8 / 8$ & $4 / 8$ \\
B (w-11 to w-20) & $7 / 7$ & $7 / 7$ & $7 / 7$ \\
\hline
\end{tabular}

Reference Laboratory panel (Table 3). The last was designed to identify any assay not up to the standard expected of third-phase $\mathrm{HBsAg}$ testing. Table 3 indicates that Mod-RIA and AUSCEL detected all the $\mathrm{HBsAg}$ positive samples present, while Hepatest detected only nine out of a possible 14 positives.

The results of testing 71200 blood donations by Mod-RIA and Hepatest over a period of 11.5 months are given in Table 5. Mod-RIA proved to be more specific (47 non-repeatable positives against 297 for Hepatest) and more sensitive (11 confirmed positives against nine for Hepatest).

MOD-RIA VERSUS EIA

Mod-RIA and Hepanostika detected all $14 \mathrm{HBsAg}$ positives in the Hepatitis Reference Laboratory panel (Table 3), although one (a weak positive of subtype D) was judged by some observers to be borderline by Hepanostika.

MOD-RIA VERSUS STANDARD RIA

Mod-RIA detected all the weakly positive samples and three of the four borderline positive samples in the FDA panel (Table 1). Sample No. 345, repeatedly negative by AUSRIA-II, gave $3 \mathrm{cpm}$ above the Mod-RIA cutoff. This sample was not retested due to insufficient volume. Complete agreement between Mod-RIA and AUSRIA-II was obtained with both AABB-CAP panels (Table 2) and the Edinburgh

Table 3 Comparison of Mod-RIA with AUSRIA-II, HEPATEST, AUSCEL, and HEPANOSTIKA using Edinburgh University Hepatitis Reference Laboratory Panel

\begin{tabular}{lccccc}
\hline & Mod-RIA & AUSRIA-II & HEPATEST & AUSCEL \\
\hline Positive & $10 / 10$ & $10 / 10$ & $9 / 10$ & $10 / 10$ \\
Weak positive* & $4 / 4$ & $4 / 4$ & $0 / 4$ & $10 / 10$ & $4 / 4$ \\
Total & $14 / 14$ & $14 / 14$ & $9 / 14$ & $14 / 14$ & $14 / 14$ \\
\hline
\end{tabular}

*Estimated by competitive double antibody RIA. ${ }^{*}$

Table 4 Comparison of Mod-RIA with AUSRIA-II using Abbott Laboratories Hepatitis Sensitivity Panel

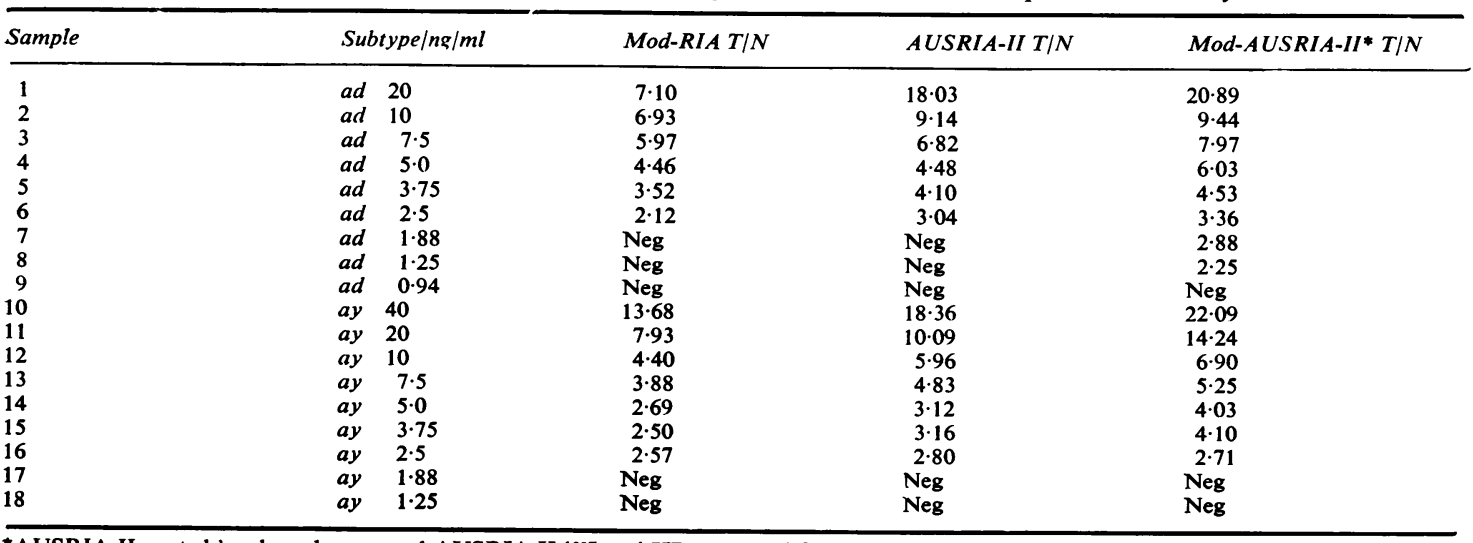

*AUSRIA-II coated beads and processed AUSRIA-II ${ }^{125}$ I anti-HBs, counted for 300 seconds. 
University Hepatitis Reference Laboratory panel (Table 3). The Abbott Laboratories Hepatitis Sensitivity panel, which consists of $\mathrm{HBsAg} / \mathrm{ad}$ $(0.94-20.0 \mathrm{ng} / \mathrm{ml})$ and $\mathrm{HBsAg} /$ ay $(1.25-40.0 \mathrm{ng} / \mathrm{ml})$, was tested using (a) standard AUSRIA-II, (b) Mod-RIA, and (c) standard AUSRIA-II beads and modified AUSRIA-II ${ }^{125}$ I antibody. Table 4 shows that for this panel the sensitivity of Mod-RIA is identical with that of standard AUSRIA-II. It is, however, of interest to note that sensitivity is improved slightly (detection of $a d / 1.88 \mathrm{ng} / \mathrm{ml}$ and $1.25 \mathrm{ng} / \mathrm{ml}$ ) when AUSRIA-II-coated beads are used in conjunction with AUSRIA-II-processed antibody, a feature probably reflecting the use of a higher affinity coating antibody; better matched for HBsAg subtypes.

Table 5 Results obtained from testing 71200 fresh blood donations by Mod-RIA and HEPATEST over an 11.5 month period

\begin{tabular}{lrr}
\hline & No. & $\%$ \\
\hline Donations tested (Mod-RIA and HEPATEST) & 71200 & - \\
Non-repeatable positives by HEPATEST & 297 & 0.42 \\
Non-repeatable positives by Mod-RIA & 47 & 0.07 \\
Repeatable HEPATEST positives confirmed & 9 & 0.012 \\
Repeatable Mod-RIA positives confirmed & 11 & 0.015 \\
\hline
\end{tabular}

Table 6 Comparative cost of reagents for AUSRIA-II, Mod-RIA, and HEPATEST

\begin{tabular}{llll}
\hline & AUSRIA-II & Mod-RIA & HEPATEST \\
\hline $\begin{array}{l}\text { Purchase price/test } \\
\text { (pence) }\end{array}$ & $74^{*}$ & $74^{*}$ & $\begin{array}{c}12 \cdot 2 \\
\text { (bulk order) }\end{array}$ \\
$\begin{array}{l}\text { Price/test after } \\
\text { processing }\end{array}$ & - & $12 \cdot 3$ & - \\
$\begin{array}{l}\text { Price/extra bead } \\
\text { Price/test of anti-HBs } \\
\text { per bead coating }\end{array}$ & - & 1 & - \\
$\begin{array}{l}\text { Total cost/Test } \\
\text { potal con }\end{array}$ & 74 & 1 & - \\
\hline
\end{tabular}

* Price may be reduced for stand/bulk orders.

†Does not include haemagglutination plates.

Note: AUSRIA-II tray may be washed and re-used.

\section{Discussion}

Development of enzymeimmunoassay may lead to a more sensitive and reliable technique than radioimmunoassay for routine $\mathrm{HBs} \mathrm{Ag}$ donor screening. For the present, however, it appears that most transfusion centres within the United Kingdom, at least, consider solid phase sandwich RIA to be the test of choice. The data presented here indicate that application of a simple biochemical purification procedure can enable any laboratory with suitable gamma counting facilities to screen all donations by RIA for a similar reagent cost per test as (bulk)
Hepatest. Mod-RIA uses the same test volumes, incubation times, and temperature as standard AUSRIA-II, although it does require the (anti-HBs) coating of extra beads and an extended counting time. The ${ }^{125}$ I-anti-HBs supplied as part of AUSRIA-II contains approximately $20 \%$ free ${ }^{125}$ I activity which contributes to the negative count and so influences the cutoff value. Removal of free ${ }^{125}$ I has the effect of reducing the negative count rate to nearer the background value, thereby allowing less radioactivity to be used per test $(20000 \mathrm{cpm}$ rather than $150000-200000 \mathrm{cpm}$ ). The processed ${ }^{125}$ I anti-HBs may then be diluted an average of 6-8-fold without loss of sensitivity. Dilution of unprocessed $125 \mathrm{I}$ anti-HBs beyond $1: 2$, on the other hand, leads to a reduction in sensitivity. Using only $20000 \mathrm{cpm} /$ test $(200 \mu \mathrm{l})$ it was found necessary to extend counting time from 1 minute to 5 minutes per bead, giving a typical negative and weak positive $(20 \mathrm{ng} / \mathrm{ml})$ count less background of 105 and 4350 respectively. While this would probably introduce an unacceptable delay on a single channel automatic gamma counter, it is quite acceptable using the NE1600. As this machine will count 16 samples simultaneously, our average daily throughput of approximately 300 samples is counted in less than 120 minutes, all results being available by mid-to-late afternoon of the day following donation.

A costing of reagents for AUSRIA-II, Mod-RIA, and Hepatest is given in Table 6. Further economies may be achieved by recovery of the processed ${ }^{125} \mathrm{I}$ anti-HBs from around the bead for re-use after being 'topped-up' with a small amount of unused processed 125I anti-HBs. Experimentation indicates that this recycling procedure may be repeated at least twice without obvious loss in sensitivity. We have, however, not employed recycled ${ }^{125} \mathrm{I}$-anti-HBs in routine donor screening.

Once a laboratory takes upon itself the responsibility of producing or modifying a reagent, it must also expect to perform sufficient quality control to ensure a product of uniformly high standard. In the case of Mod-RIA the areas requiring quality control are (a) bead coating, (b) ${ }^{125 I}$ anti-HBs processing, and (c) evaluation of the complete assay using standardised positive and negative controls, which should be included in each day's testing, and, if possible, regular assessment via coded proficiency panels such as those supplied by the American Association of Blood Banks, in conjunction with the College of American Pathologists.

Another important consideration for laboratories contemplating large-scale use of RIA is the amount of isotope it will be necessary to store and to handle. Legislation in the United Kingdom requires certification (grade $\mathrm{C}$ ) for any laboratory holding more 
than $5 \mu \mathrm{Ci}{ }^{125}$. Many blood transfusion hepatitis laboratories contemplating RIA donor screening will find this limit unrealistic, since a 100-test AUSRIA-II kit contains almost $15 \mu \mathrm{Ci}$ of ${ }^{125} \mathrm{I}$ activity. By contrast processed ${ }^{125} \mathrm{I}$ anti-HBs sufficient for 100 tests contains only $1.9 \mu \mathrm{Ci}$ of radioactivity.

In the South-East of Scotland the HBsAg detection rate among first-time blood donors is $0 \cdot 12 \%$ (1:770) by Mod-RIA. During almost one year's testing the overall (regular donors plus first-time donors) detection rate by this technique was $0.015 \%$ (1:6472). The 8-fold difference is the result of several years of HBsAg screening during which many positive donors have been identified and removed from the donor panel. It is interesting to note that Hepatest detected only two $(22 \%)$ fewer true HBsAg carriers than did Mod-RIA, albeit giving six times as many non-repeatable positives (Table 5). These findings are similar to those of Barbara et al. ${ }^{5}$ who detected only $11 \%$ more carriers by RIA than by Hepatest, as a result of screening 39962 blood donations.

The identification of only two extra HBsAg carriers in the course of a year's donor screening may hardly seem to justify a move from Hepatest to RIA, particularly if extra reagent costs are incurred. It should be borne in mind, however, that the cost of Mod-RIA reagents is little more than the cost of Hepatest purchased in bulk. In addition, if blood from one or both of those extra carriers had been transfused or plasma pooled for fractionation and subsequently caused acute or asymptomatic hepatitis with the possible development of another carrier(s), the potential cost to the Health Service and to society would more than justify the move to a more sensitive screening test.

Although this report is primarily concerned with the protocol and performance of Mod-RIA as a test for use on donor serum, experience has shown that it is well suited to testing plasma pools and blood products for HBsAg. In the latter instance, particularly with intermediate factor VIII, the initial incubation period should be extended to 60-70 hours at a temperature of $15-20^{\circ} \mathrm{C}$, if false-positive results are to be avoided.

For laboratories with access to iodination facilities, it may well prove cost-effective to produce and quality control ${ }^{125} \mathrm{I}$-anti-HBs for use in donor screening. The Mod-RIA procedure described here is aimed at those laboratories that are without such facilities and which cannot currently afford commercial RIA for routine donor screening.

We thank those individuals and organisations who supplied the HBsAg proficiency panels used in this study.

\section{References}

${ }^{1}$ Ukkonen P, Koistinen V, Penttinen K. Enzymeimmunoassay in the detection of hepatitis B surface antigen. J Immunol Methods 1977; 15: 343-353.

${ }^{2}$ Kačaki J, Wolters G, Kuijpers L, Stulemeyer S. Results of a multicentre clinical trial of the solid phase enzyme immunoassay for hepatitis B surface antigen. Vox Sang 1978; 35: 65-74.

${ }^{3}$ Adachi H, Fukuda T, Funahashi S, Kurahori T, Ishikawa E. Sandwich enzymeimmunoassay of hepatitis B surface antigen (HBsAG). Vox Sang 1978; 35: 219-223.

${ }^{4}$ Hopkins R, Ross S, Jordan T, Watt A D. Comparison of radioimmunoassay and enzyme immunoassay for detecting hepatitis B surface antigen in serum from freshly donated blood and selected blood products. J Clin Pathol 1978; 31 : 1000-1002.

${ }^{5}$ Barbara J A J, Howell D R, Cleghorn T E, Cameron C H, Briggs M, Dane D S. A comparison of different methods of screening blood donations for HBsAG. Vox Sang 1977; 32: 4-9.

${ }^{6}$ Watt A D, Robertson M, Hopkins R. Bulk preparation of reagents for hepatitis B testing. J Clin Pathol 1976; 29: 364-366.

${ }^{7}$ Chrystie I L, Islam M N, Banatvala J E, Cayzer I. Clinical evaluation of the turkey-erythrocyte passivehaemagglutination test for hepatitis-B surface antigen. Lancet 1974; 1 : 1193-1194.

${ }^{8}$ Leers W D, Kouroupis G M. Comparison of the reversed passive haemagglutination with radioimmunoassay methods for hepatitis B antigen. $J$ Clin Microbiol 1975; 2: 8-10.

${ }^{9}$ Burrell C J, Leadbetter G, Black S H, Hunter W M. Rapid detection of hepatitis $B$ surface antigen by double antibody radioimmunoassay. $\mathrm{J}$ Med Virol $1978 ; 3: 19-26$.

Requests for reprints to: Dr Robert Hopkins, Microbiology Division, South-East Scotland Regional Transfusion Centre, Royal Infirmary, Edinburgh, UK. 